Article

\title{
Search for the waterfalls in Ethiopia using remote sensing data
}

\author{
Alexey V. Kutuzov
}

I.D. Papanin Institute for Biology of Inland Waters, Russian Academy of Sciences, Borok 109, Nekouz District, Yaroslavl' Region, 152742 Russia

kutuzov-st@yandex.com

Received: 25.03.2020

Revised: 07.12.2020

Accepted: 07.12.2020

Published online: 02.02.2021

DOI: $10.23859 /$ estr-200325

UDC 87.35.02:89.57.45

Translated by D.M. Martynova
Abstract. Waterfalls are specific hydrological and hydrobiological objects that often serve as the natural obstacles for spreading of aquatic animal species, resulting as discontinuous range of these species. Waterfalls and rapids create special habitats for riverine aquatic organisms and cause microclimatic changes along the coast. The areas of the largest waterfalls in Ethiopia, highmountainous Jinbar Waterfall and low-mountainous Blue Nile Falls (Tis Abay, Tis Issat), were considered as model. Up-to-date remote sensing and GIS for processing and storing satellite and field data makes it possible to identify new waterfalls and rapids, to correct and to supply the existing literature and cartographic data. ERS data obtained from the modern satellite Sentinel-2, designed to monitor the state of the environment, as well as data from radar satellite imagery (SRTM) were used mainly. Based on the results of the analysis of cartographic materials and remote sensing data, the localization of a number of large waterfalls and rapids on the rivers of the Ethiopian Highlands was determined and the parameters for the selection of remote sensing data were established. Images with a spatial resolution of $10-15 \mathrm{~m} / \mathrm{pixel}$ and higher are suitable for detecting significant waterfalls (more than $30-\mathrm{m}$ wide). According to the present study, the identifying the waterfall zones by the methods of GIS analysis of topographic maps at a scale of 1:200000 and larger, as well as from satellite topographic data is possible.

Keywords: rivers, image interpretation, satellite images, remote sensing, ERS, GIS, DEM.

To cite this article. Kutuzov, A.V., 2021. Search for the waterfalls in Ethiopia using remote sensing data. Ecosystem Transformation 4 (1), 10-19. https://doi.org/10.23859/estr-200325

\section{Introduction}

The study and search for waterfalls as the specific hydrological objects attracts much attention of specialists from different fields, including biologists. Large waterfalls are the natural obstacle for spreading of aquatic animal species, they often lead for breaking-up of their populations, and thus reduce indirectly the species diversity in the upper reaches of rivers (Levin et al., 2019; Roberts and Khaironizam, 2008). High humidity and mist spreading far in the air near large waterfalls promote the formation of specific phytocenoses that include bryophytes, ferns, and other terrestrial hydrophilic vegetation (Abebe et al., 2020; Djan-Chekar, 1993).

Waterfalls are extremely diverse by their genesis, height and many other parameters, but a sharp drop in height in the river bed (up to many hundreds of meters) is a common characteristic for all waterfalls. Insignificant differences in height in the channel of the 
water flow (less than $1 \mathrm{~m}$ ) are usually classified as ledges and rapids.

Data on the number and location of waterfalls are very limited, largely due to the inaccessible mountainous terrain where they are usually located. Groundbased mapping is often extremely difficult here, but Earth remote sensing (ERS) data from a satellite may facilitate solving this issue. The present study aims to verify the possibility of using modern remote sensing data to search for relatively small objects of the river area, for example, the river barriers (rapids and waterfalls).

\section{Object of study}

Ethiopia is a mountainous African country, it has the largest waterfalls on the continent. The most part of its territory is occupied by the Ethiopian Highlands, where the average height exceeds $2000 \mathrm{~m}$ and many mountains higher than $4000 \mathrm{~m}$ (the highest point is Mount Ras Dejen (Ras Dashen), 4620 m). Annual precipitation ranges from $50 \mathrm{~mm}$ (in the northern and eastern areas) to $1500-1800 \mathrm{~mm}$ (in the central regions and in the south-western part). Most precipitation falls in the central Ethiopia in summer, in the southern areas, in spring and autumn (Alhamsry et al., 2020).

The Blue Nile Falls (Tis Abay, Tis Issat, "Great Smoke" in Amharic) is a low-mountainous waterfall cascade ( $\mathrm{N}$ 11.49076, E 37.58775), located on the outflow from the Lake Tana, the Blue Nile River (tributary of the Nile River). Depending on the precipitation and the season, the height of the large upper waterfall varies from 37 to $45 \mathrm{~m}$, the width, from 100 to $400 \mathrm{~m}$. This group of waterfalls reaches the maximum height and width during the rainy season (June - September), when each waterfall turns into a powerful stream (Figs. 1, 2, 3).

High-mountainous Jinbar Waterfall (N 13.23941, $E$ 38.07474) is located in the rugged terrain of the northern part of Ethiopia, in the Simien Mountains National Park. The waterfall is formed by the relatively short mountain Jinbar River, its length slightly exceeds $8 \mathrm{~km}$. The stream falls from a height of approximately $500 \mathrm{~m}$; the exact height of the waterfall is still unknown due to its inaccessible location (Figs. 1,4). Water falls from the rocks as a strong single-jet stream; in the middle, the waterfall crashes against the rock ledges and scatters as tiny splashes in different directions, forming a permanent water cloud. Like many waterfalls, the power of the Jinbar Waterfall depends on the rainy season, i.e. the most powerful flow is observed in late summer.

\section{Materials and methods}

Diverse cartographic data were selected, developed, and analyzed in order to study approaches to the search for waterfalls in Ethiopia, including heterogeneous satellite images, topographic maps, and vector GIS data. Raster data of multispectral ima- gery by the Sentinel-2 satellite were obtained from the EarthExplorer resource (www.earthexplorer.usgs. gov) taking into account the survey periods (rainy and drought seasons). Topographic maps and elevation data from the international space projects SRTM, Aster GDEM (Version 3), and ETOPO2 were used as well. Open sources of basic vector data on the territory of Ethiopia, as well as materials from the OpenStreetMap project were also included.

The exact coordinates of rapids and waterfalls were calculated by GIS objects developed on the open map services, such as Yandex.Maps, Google Maps, and some others. Satellite images of medium (10-15 m/pixel) and high spatial resolution (up to $0.6 \mathrm{~m} / \mathrm{pixel}$ ), temporal resolution (up to 15 days), and radiometric resolution (up to 1624 bits) were obtained for certain waterfall areas. Based on these materials, the final GIS data layers were formed, containing maps of slope angles in the terrain, as well as the geographical objects, i.e. the rivers and waterfalls (rapids). There are practically no publications with exact coordinates of waterfalls, so the original search algorithm was applied. The exact coordinates of two famous large waterfalls in Ethiopia (high- and low-mountain) were determined by searching for information on various Internet resources (for example, databases: Vodopady, 2020; World Waterfall Database, 2020) with subsequent confirmation in map services (Yandex.Maps, Google Maps), according to topographic maps; finally, the coordinates were specified according to satellite images.

The studies of Indian specialists, who use the elevation data from the SRTM project for studying water bodies, are the closest to the topic of our research; however, the attention of our colleagues is focused on the general characteristics of drainage basins and the identification of tributaries of the main watercourse of different orders (Ajay et al., 2020; Munir, Iqbal, 2016; Kant et al.,), while methods for detecting waterfalls using altitude data are not described in the literature so far.

\section{GIS methods and materials}

A number of approaches have been proposed and tested to determine the principles of searching for unknown waterfalls and rapids on the rivers using different types of satellite data.

The main satellite images used in the study are: (1) EarthExplorer (data of the open map service), 11 images, mainly November-February 2004-2020, and (2) Sentinel-2 with a resolution of $10 \mathrm{~m} / \mathrm{pixel}$, 3 images (February 1, 2018, November 13, 2018, and November 3, 2016, which were the dates of high water level and low cloudiness). According to our previous studies (Kutuzov, 2011), mainly the images in the infrared range, the visible range, and the panchromatic channel were used as auxiliary ones. Pan-sharpening was not used for image analysis, since its main purpose is to improve the visualization 


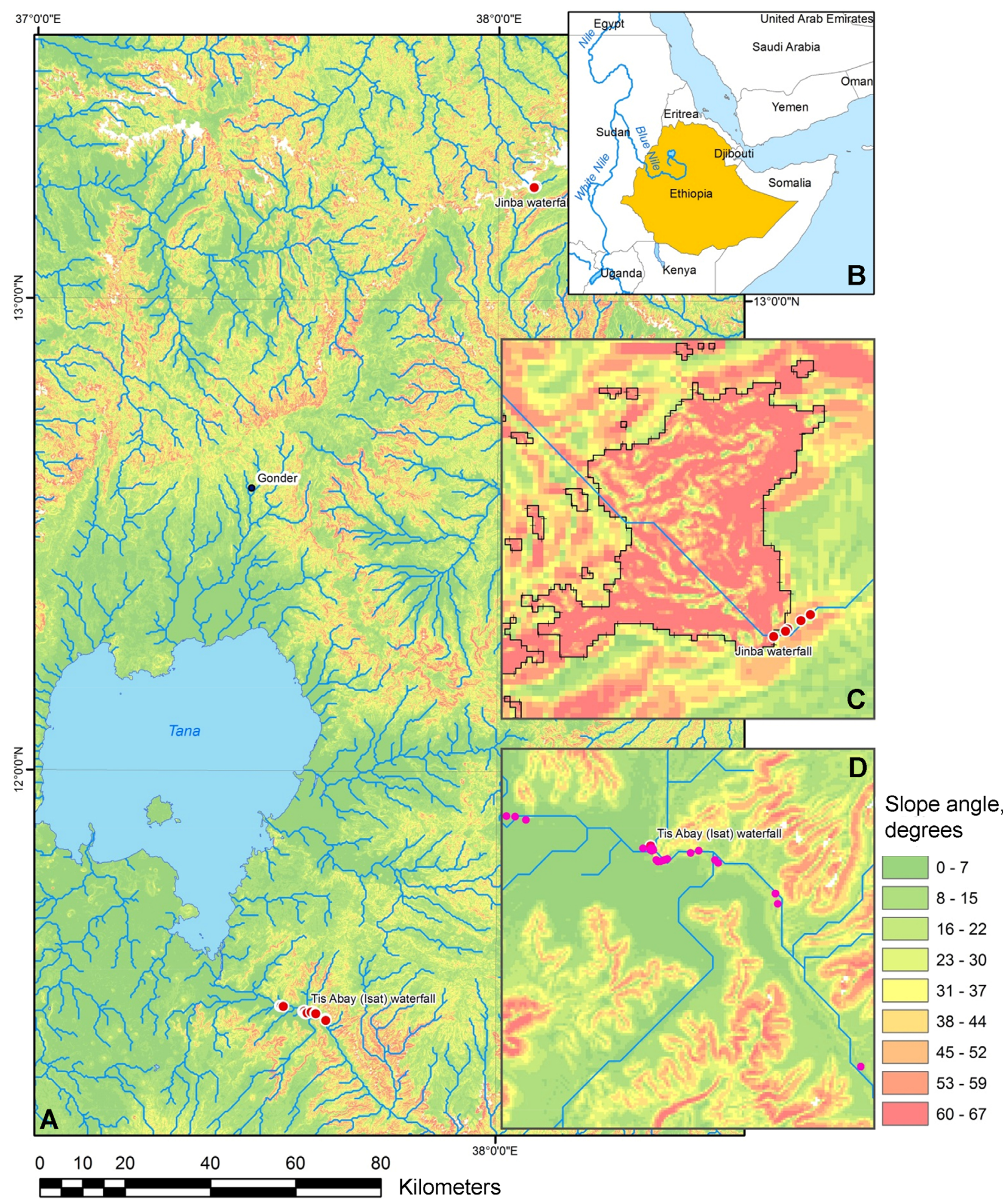

Fig. 1. The position of the studied Jinbar Waterfall and Blue Nile Falls on a map of Ethiopia. A (background layer) - GIS data of relief analysis, slope angle map (scale 1:1000000); B - location of the study area in Ethiopia (the vicinity of the Lake Tana, scale 1:40000000); C - position of Jinbar Waterfall (scale 1:22000); D - position of the Tis Abay Waterfall (scale 1:45000). Main waterfalls and adjacent waterfall areas are marked in red. 
of a multichannel image using a panchromatic image of a higher spatial resolution, but at the expense of spectral accuracy. In the Sentinel-2 satellite images, the maximum spatial resolution is used for separate channels of the visible and infrared spectrum. QGIS 3 and ArcMap 10 software was used for GIS analysis of spatial data.

Waterfalls and fast-flowing rapids of the river section (Fig. 3) were determined using the high resolution satellite images; the coordinates of the largest waterfall were determined from literature data and refined by remote sensing data. GIS analysis was carried out using Sentinel-2 medium spatial resolution satellite images; after their preliminary processing, anomalously light areas were revealed within the river channel. Their position on the developed map of slope angles in the relief was analyzed. In order to perform a detailed study of the identified areas, high-quality images with high spatial resolution were subsequently selected. Such high-resolution images, where a certain and relatively small section of the river was well presented, were usually rare or sporadic.

\section{GIS analysis of the relief, the map of slopes}

The area model was developed using the topographic data, mainly from the elevation data of the SRTM (Version 3) and Aster GDEM projects. Calculation of the derived characteristics of the surface made it possible to make a map of the slope angles using the algorithms of the specialized GIS module (Spatial analyst - Slope, ArcGIS). The vectorization of the raster image was carried out for the zoning of the territory, accompanied by the splitting of the satellite image into thematic layers; then spatial operations were performed to identify the zones of interest, i.e. the river bed, mountain areas with steep slopes, spurs of mountain ranges, and others (Figs. 1, 3). When working with different data sources, the GIS "Overlay" tools were often used to determine the geometric intersection of a number of objects, such as particular datasets of elevation data, river channels, and locations of waterfalls and rapids (Figs. 1, 7).

An angle of deviation from nadir up to $30^{\circ}$ is admissible for satellite images used for developing a digital DEM relief model; however, for the mountain waterfalls under consideration, this angle should not exceed $15^{\circ}$ (in the case of the Jinbar Waterfall, no more than $2^{\circ}$ ). The panoramic images with an angle of deviation from nadir up to $60^{\circ}$ are admissible for weakly and moderately rugged terrain.

The elevation data of the SRTM and Aster GDEM projects contain anomalies and artifacts, which complicates their applicability, when great errors in elevation data are often found when analyzing small areas (Geograficheskie..., 2020). Other datasets are used to replace missing or abnormal values for one of the resources. In particular, in our study, we have used the data from topographic maps and ETOPO2.

\section{Results and discussion}

The map of slope angles in the relief was developed using a standard GIS module (Burrough, 1998), based on the topographic survey data of the territory by a special radar system of the SRTM project and on the ETOPO2 database additionally (Fig. 1). The data on the location of lakes, rivers, cities, and countries was obtained from the open sources. A raster data layer was applied to the map, which displayed the developed map of slope angles for the terrain (scale 1:1000000), as well as a vector point layer (the locations of the detected waterfalls and large rapids). The maps of the location of the study area in Ethiopia (the vicinity of the Lake Tana) and the position of waterfalls (highmountainous Jinbar Waterfall and low-mountainous Blue Nile Falls) were developed separately in different scales and were shown on the insets, from top to bottom: 1:40000000; 1:22000; and 1: 45000 (Fig. 1).

The slope angles map (Fig. 1) clearly shows the areas of different types, from slightly rugged (green: slope angles $0-13^{\circ}$ ) to mountainous areas with high steep slopes (red: slopes $28-67^{\circ}$ ). The elevation data is not available for some areas with extremely rugged terrain; for example, it is the Jinbar Waterfall, which falls from sheer cliffs. Apparently, the adjacent river flow means a transition to a waterfall that breaks down from the rocky walls for such zones, since latter are characteristic of significant and sharp changes in altitude. SRTM elevation data may be missing or erroneous here; the corrected and extrapolated Aster GDEM (Version 3) datasets have been used to replace the incorrect values (such areas near the Jinbar Waterfall are marked with a black border).

The appearance of waterfalls at points of approach of rocky ledges is a feature of the flattened sections of low-mountainous river valleys, found for the Blue Nile Falls and for a series of adjacent waterfalls on a fragment of a topographic map and a slope angle map (Fig. 3).

\section{Blue Nile Falls (Tis Abay)}

The high-resolution image (Fig. 2) shows waterfalls on dams and bypass channels (transverse white stripes and spots) and the same two large white jets of water on the photograph.

Manual search for waterfall areas using high spatial resolution remote sensing images placed on the open map services (Yandex.Maps, Google Maps, and others) turned out to be the most effective method when analyzing relatively small area of the proposed field research. In our study, dam waterfalls usually appear on such images as a narrow whitish strip across the river bed, and waterfalls, as compact light spots (Fig. 2). Rapids have been recognized as long stretches along the riverbed. 

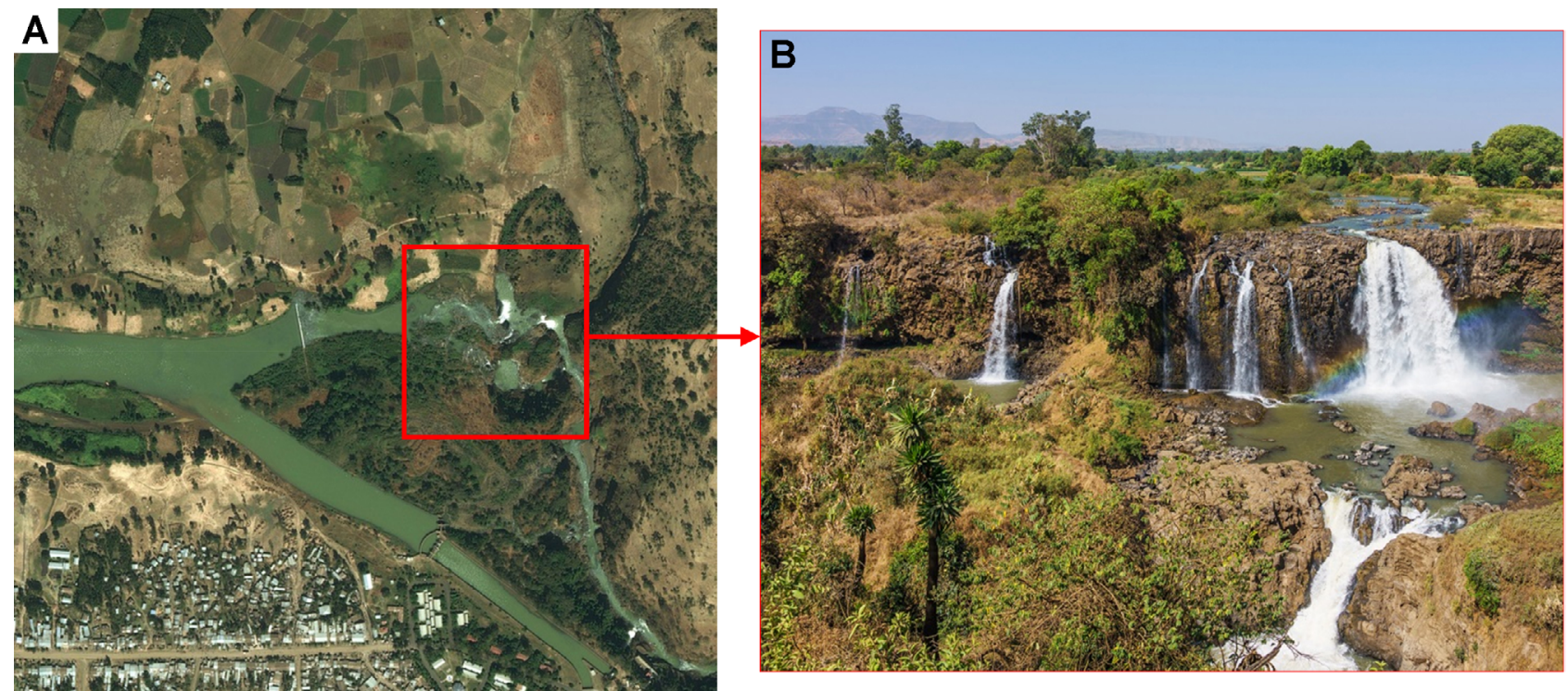

Fig. 2. South Gondar Zone, Amhara Region, Ethiopia. Blue Nile Falls (Tis Abay, Tis Issat). A - photo, B - space image, both taken from Yandex.Maps. The place of the picture taking and the direction of the look are indicated in red.

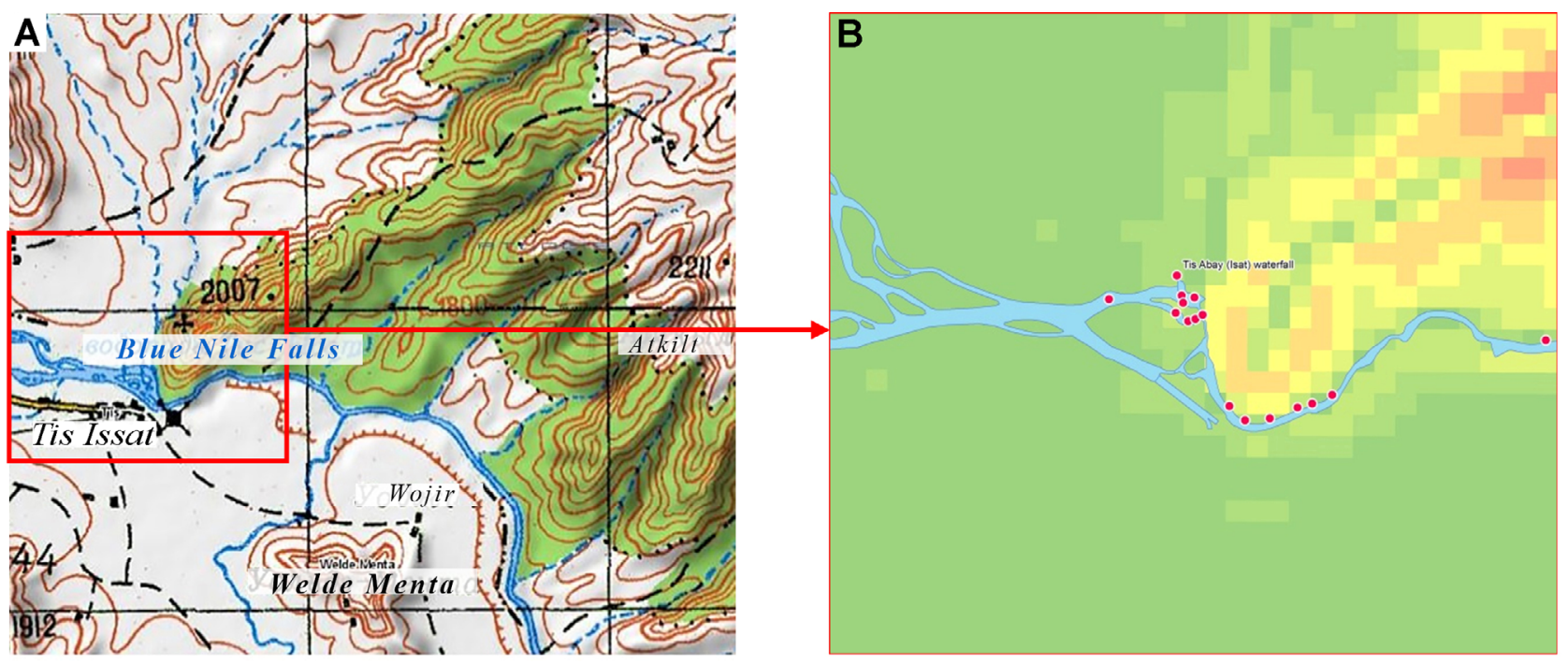

Fig. 3. Tis Abay (Tis Issat). A - fragment of a topographic map; B - same plot on the developed slope map. Red dots indicate waterfalls and rapids. 
Waterfalls are common where the river bed meets the spurs of mountain ranges (Fig. 3). The topographic map fragment and slope map (Fig. 3) show a series of large waterfalls and rugged rapids where the Blue Nile River makes its way through rocky terrain. Waterfall zones on this fragment of the river have been identified using high-resolution remote sensing data, and the coordinates of the main waterfall, known from the literature, have been checked using satellite images.

\section{Jinbar Waterfall}

In this waterfall, water falls from the rocks as a strong narrow single-jet stream, breaking in the middle on the rock ledges. This type of waterfall was rarely recognized on satellite imagery; in particular, one needed the correct season (local high water season) to select the proper images. The visibility of such a high waterfall on satellite images may depend strongly on both the direction and strength of the wind blowing off the water streams and water dust clouds at the time of shooting, as well as on the angle of deviation from the nadir during satellite imagery of the location of the waterfall (Fig. 5). Such steep slopes and narrow high-mountainous gorges demand the angle of deviation from the nadir of no more than $2^{\circ}$ for correct recognition of the waterfall section. Such successful satellite images are found rarely. On the map and satellite image of the Jinbar Waterfall (Fig. 6), one can see that the river bed of the Jinbar River turns almost at a right angle after the waterfall, to the northwest. The volumetric satellite image (3D visualization of the relief based on the DEM) of this territory clearly shows a mountain cliff and an adjoining river: this is the place where the waterfall appears (the red circle is the position of the waterfall).

Seasonal images of Sentinel-2 satellites taken in 2018 and the results of their processing are presented at Fig. 7. A water mask has been developed to decipher the waterfalls on the basis of the image in the infrared range, then a vector data layer, "water", has been developed as well (Fig. 7, green color). Here, the riverbed and the channel area (green polygon) and the main riverbed (blue line, source: www.openstreetmap. org) are shown. Further, the geometric intersection of these two objects has been determined to define the area of their overlap; minor water bodies have been excluded during this process. The points are the locations of the already known waterfall sections and rapids; they coincide with the breaks in the resulting "river bed" polygon. GIS analysis of the cross-country flow of a river channel makes possible to identify the areas of calm flow (continuous fragments) and seething flows (interruptions). This methodological approach to the analysis of the state of the watercourse allows using a semi-automatic mode for mapping prospective waterfalls on the rivers using infrared data.
The use of different types of elevation data (Fig. 6) for developing a digital elevation model (DEM) and combining them with GIS data on the rivers is the basis for the subsequent automation of the process of identifying such relatively small objects as potential waterfall areas. In order to confirm the presence of waterfalls, high spatial resolution images will be needed, namely, the corresponding fragments of satellite images or aerial photographs, including those from drones (UAVs). The use of regularly updated remote sensing data of medium spatial resolution (for example, the Sentinel-2A and Sentinel-2B satellites) makes it possible to monitor seasonally the state of identified waterfalls by series of images with a time interval of up to 5 days.

\section{Conclusions}

Rivers located in the terrains characterized by large slope angles in the relief have numerous waterfalls and rapids, which may be detected by GIS analysis of remote sensing data. Based on the data of radar topographic survey of the study area by the specialized SRTM satellite and by the ETOPO2 project additionally, a map of slope angles for mountainous areas with a varied landscape has been developed.

GIS analysis of the way of the river channel over highly rugged terrain is possible in a semi-automatic mode, which allows one to obtain a map of the areas of the estimated position of waterfalls on the rivers based on altitude data on the relief.

Measured (real) satellite elevation data are not available for a number of areas with difficult terrain; for such zones, additional cartographic materials and appropriate GIS processing are needed. For most of these complex mountainous areas, there are already updated versions of the original radar survey with calculated (extrapolated) elevation data (e.g., www. earthexplorer.usgs.gov). On the rivers, near such zones with significant and sharp changes in altitude, one can expect the presence of waterfalls like Jinbar Waterfall. Such high falling waterfalls are found only in rare cases when using remote sensing methods in the optical range only.

Based on the results of the GIS analysis of the slope angles, it has been shown also that waterfalls and rapids in low-mountainous river valleys often appear at the points of approach of rocky outcrops on the flattened areas; for example, these are the Blue Nile Falls (Tis Abay, Tis Issat) and a series of adjacent waterfalls. In small areas, the search for waterfalls may be more effective in manual mode on high spatial resolution images in visible or infrared range. Such waterfalls may look like transverse light stripes and spots against a dark background of calmly flowing water; rapids are recognized as extended light areas along the riverbed. The slope angle for the threshold 


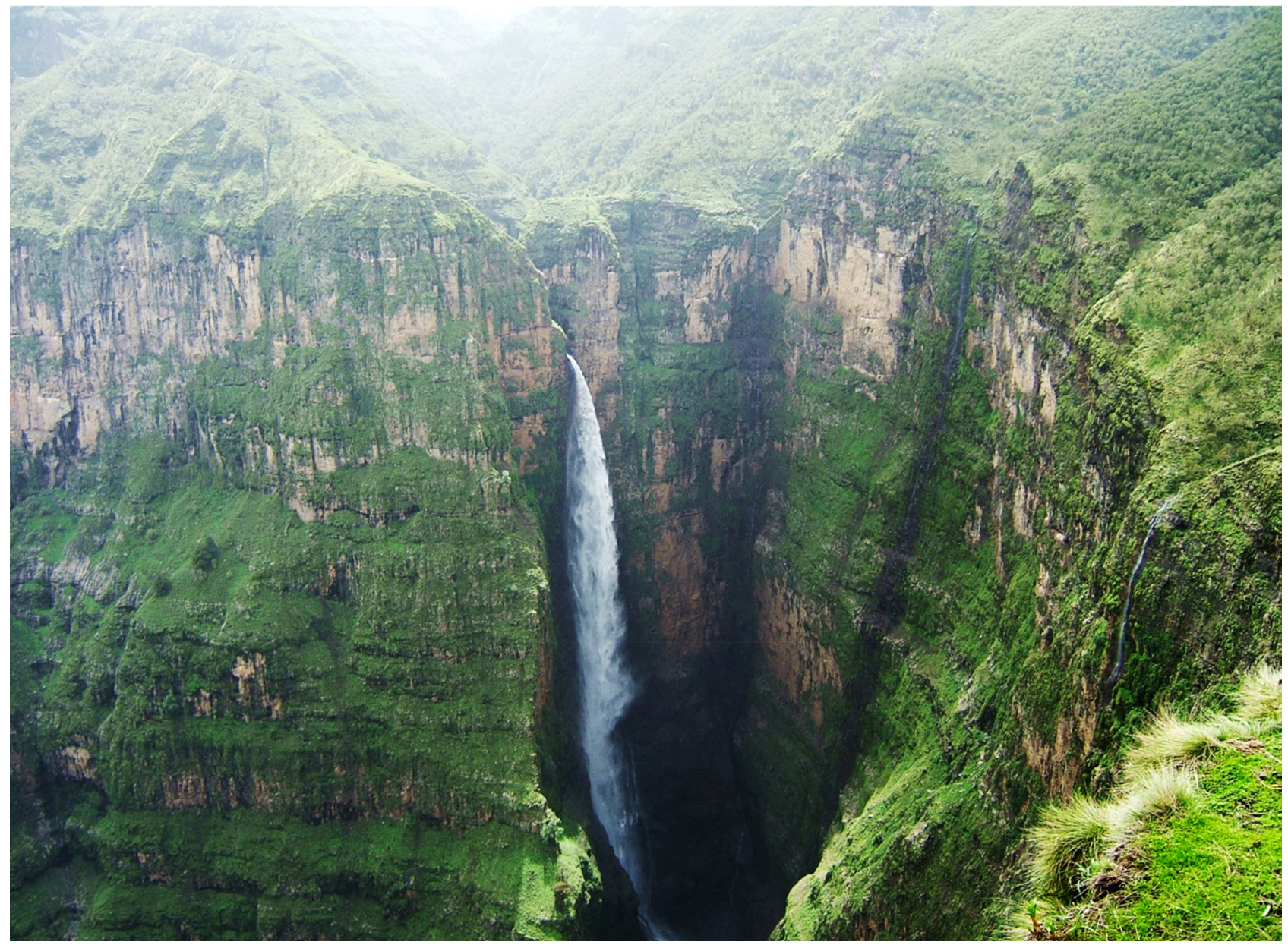

Fig. 4. North Gondar Zone, Amhara Region, Ethiopia. Photo of the Jinbar Waterfall.

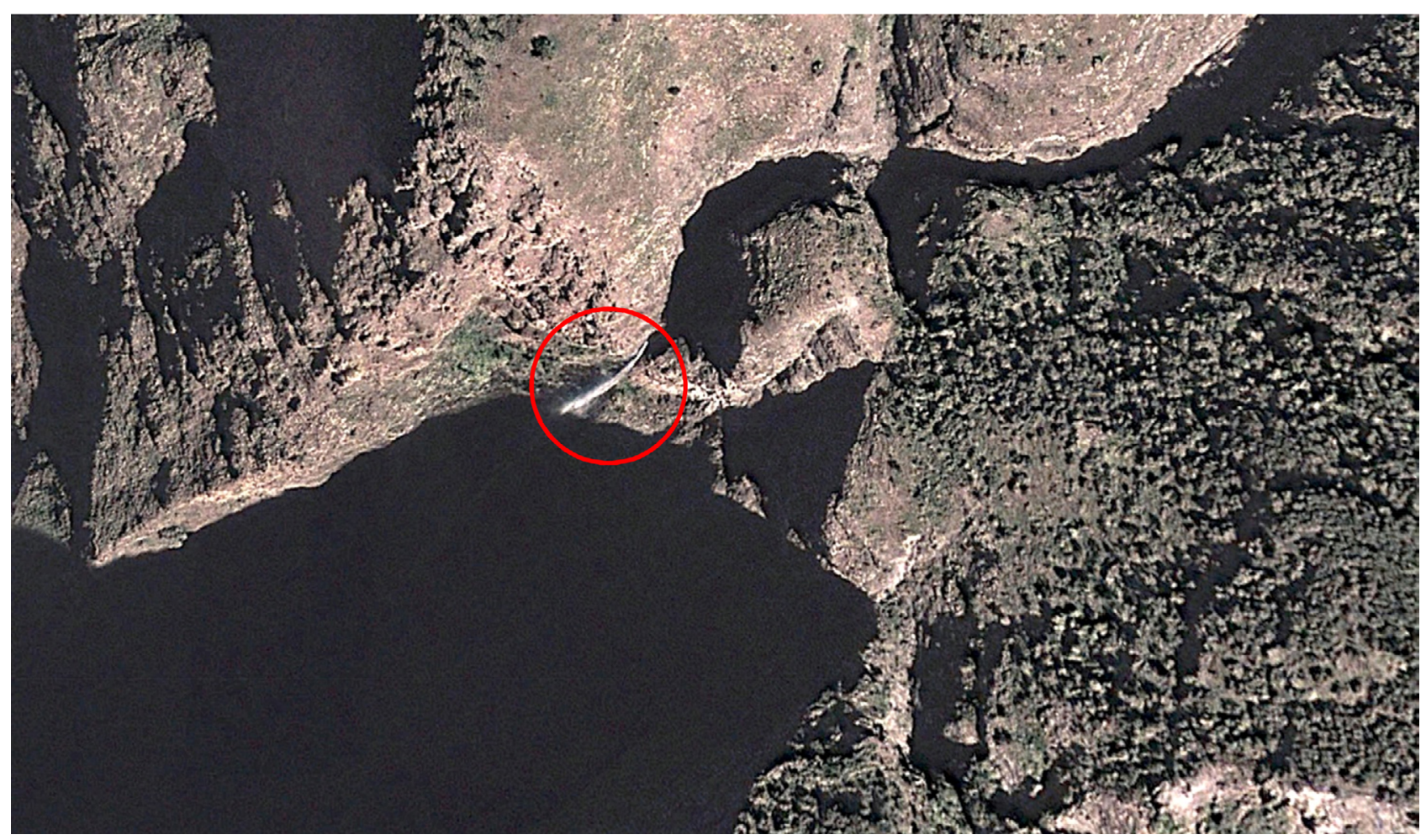

Fig. 5. North Gondar Zone, Amhara Region, Ethiopia. High spatial resolution satellite image $(0.6 \mathrm{~m} / \mathrm{pixel})$ of the Jinbar Waterfall. The center of the image is highlighted in red. 

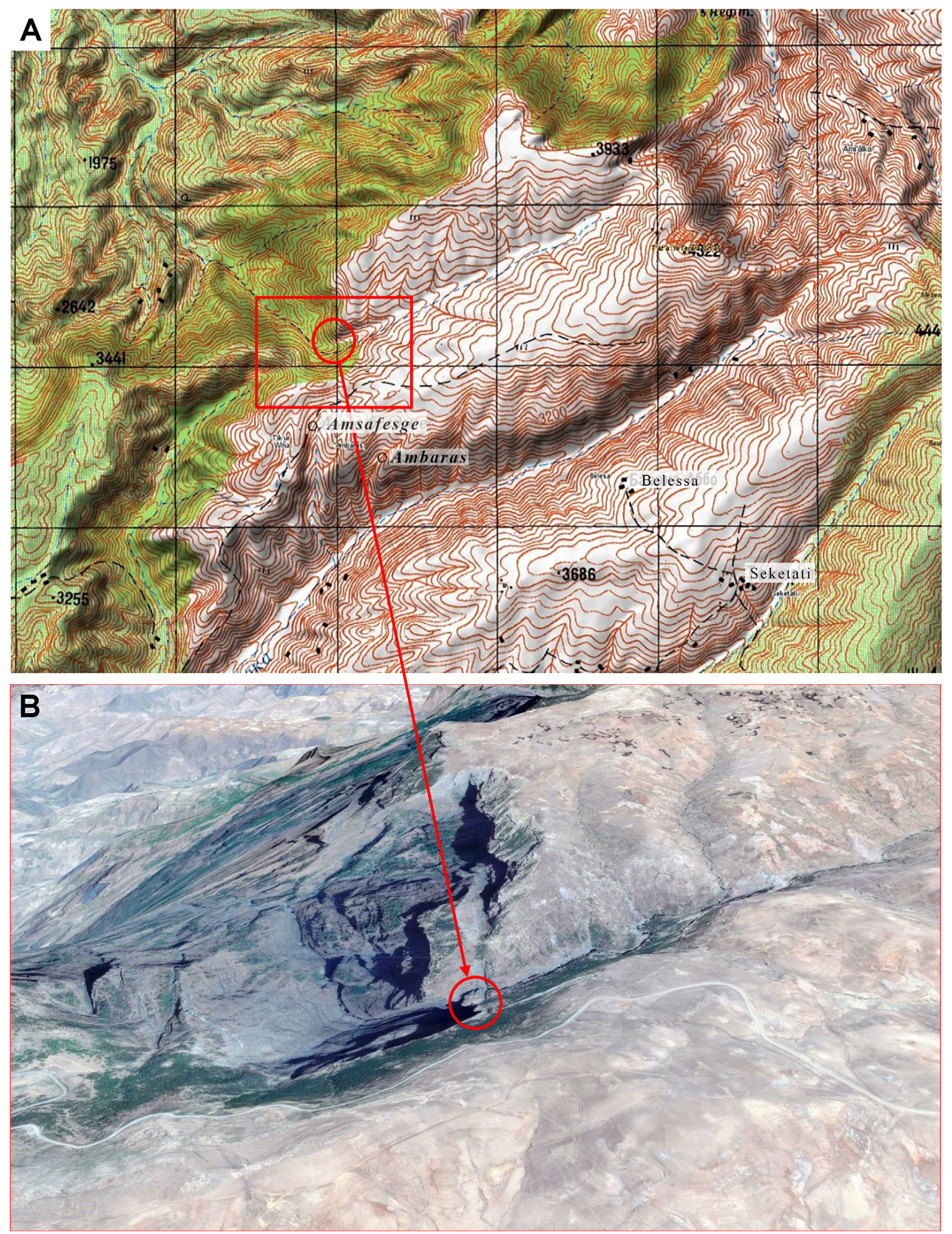

Fig. 6. Jinbar Waterfall, general position in the relief: A - topographic map (scale 1:200000) (hypsometry), B - 3D model of this area at a satellite image. The red circle indicates the position of the waterfall. 


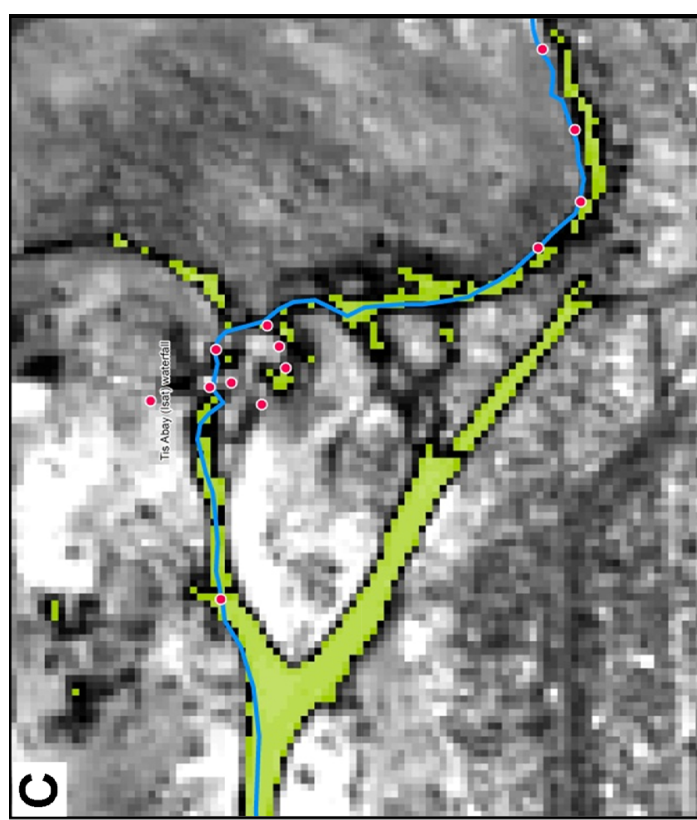

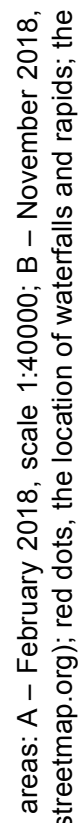

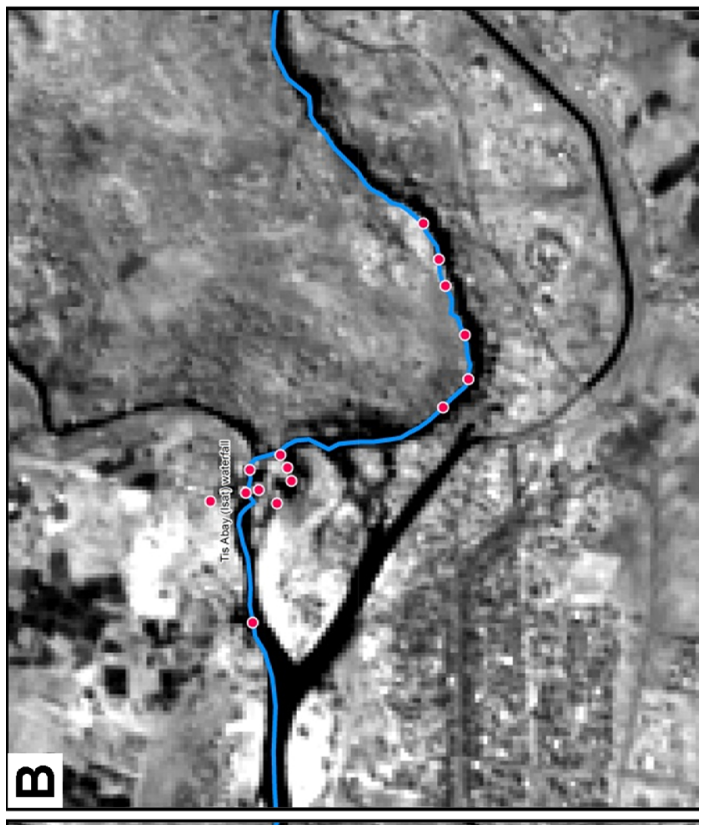

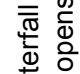

$\stackrel{\pi}{3}$

年

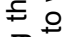

응

는 응

过

호

के

造

$\circ$

는

吕.

可

is $\cong$

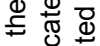

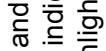

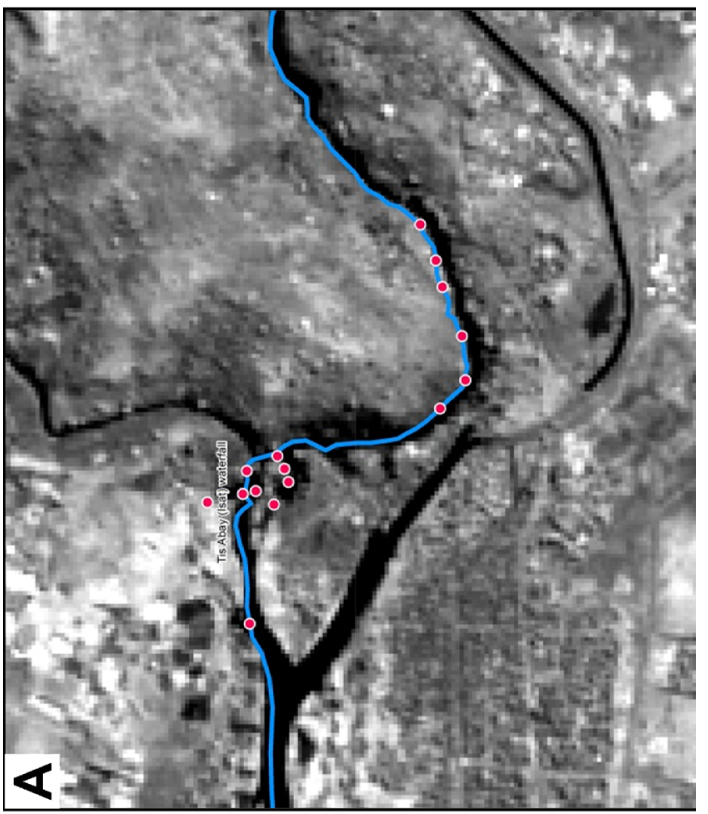

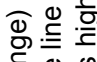

돈

递

준 $\frac{\pi}{\circ}$

ㅇํㅇ

焉

屯

$\sim 0$

这

吾㝘

क㐫

पे

\&) ه

당

त)

ㅎํㅇㅎㅁ

के ठ ठ

드응

은 $\frac{0}{\mathbb{N}}$ 
in such a picture may be estimated by the brightness of the pale elongated spot: the higher the brightness, the higher the slope steepness.

The semi-automatic recognition of river sections with waterfalls more than $30-\mathrm{m}$ wide from a series of space images in the optical range (spatial resolution $10-15 \mathrm{~m} /$ pixel) is also possible. Additional expert analysis of single high spatial resolution images is required to confirm the presence of waterfalls and rapids in these potentially waterfall areas.

The use of regularly updated remote sensing data of medium spatial resolution (for example, Sentinel-2) makes possible further seasonal monitoring of the state of previously identified waterfalls based on a series of images.

\section{ORCID}

Alexey V. Kutuzov (iD 0000-0003-2296-7549

\section{References}

Abebe, W., Tilahun, S., Moges, M., Wondie, A., Derseh, M. et al., 2020. Hydrological Foundation as a Basis for a Holistic Environmental Flow Assessment of Tropical Highland Rivers in Ethiopia. Water 12 (2), [547]. https://doi.org/10.3390/w12020547

Alhamshry, A., Fenta, A.A., Yasuda, H,. Kimura, R., Shimizu, K., 2020. Seasonal rainfall variability in Ethiopia and its long-term link to global sea surface temperatures. Water 12 (1), 55. https://doi. org/10.3390/w12010055

Burrough, P.A., McDonell, R.A., 1998. Principles of Geographical Information Systems. Oxford University Press, New York, USA, 190 p.

Djan-Chekar, N., 1993. The bryophyte flora of Bridal Veil Falls, British Columbia: an analysis of its composition and diversity. Master Thesis. University of British Columbia, Vancouver, Canada, 134 p. https://open.library.ubc.ca/collections/ubctheses/831/items/1.0086098

EarthExplorer, 2020. U.S. Geological Survey. Web page. URL: https://earthexplorer.usgs.gov (accessed: 28.02 .2020$)$.

Geograficheskiye informatsionnyye sistemy i distantsionnoye zondirovaniye [Geographic information systems and remote sensing]. Web page. URL: https://gis-lab.info/qa/aster-gdem.html (accessed: 28.02.2020). (In Russian).
Kant, S., Singh, S., Nema, S.K., Meshram, S., 2015. Morphometric analysis of Sonar sub-basin using SRTM data and geographical information system (GIS). African Journal of Agricultural Research 10 (12), 1401-1406. https://doi.org/10.5897/ AJAR2013.7907

Kutuzov, A.V., 2011. Ispol'zovaniye dannykh distantsionnogo zondirovaniya dlya monitoringa sistem "voda - susha" na ravninnykh vodokhranilishchakh (na primere Tsimlyanskogo vodokhranilishcha) [Using of remote sensing data for monitoring of "water - land" systems for plain reservoirs (by an example of the Tsimlyansk Reservoir)]. Issledovaniye Zemli iz Kosmosa [Study of Earth from space] 6, 64-72. (In Russian).

Levin, B.A., Casal-López, M., Simonov, E., Dgebuadze, Y.Y., Mugue, N.S. et al., 2019. Adaptive radiation of barbs of the genus Labeobarbus (Cyprinidae) in an East African river. Freshwater Biology 64 (10), 1721-1736. https:// doi.org/10.1111/fwb.13364

Munir, B.A., Iqbal, J., 2016. Flash flood water management practices in Dera Ghazi Khan City (Pakistan): a remote sensing and GIS prospective. Natural Hazards 81, 1303-1321. https://doi. org/10.1007/s11069-015-2136-5

Roberts, T.R., Khaironizam, M.Z., 2008. Trophic polymorphism in the Malaysian fish Neolissochilus soroides and other old world barbs (Teleostei, Cyprinidae). Natural History Bulletin of the Siam Society 56 (1), 25-53.

Singh, A.P., Arya, A.K., Singh, D.S., 2020. Morphometric analysis of Ghaghara river basin, India, Using SRTM Data and GIS. Journal of The Geological Society of India 95, 169-178. https:// doi.org/10.1007/s12594-020-1406-3

Vodopady [Waterfalls], 2020. Web-page. URL: http:// www.vodopads.ru/blog/vodopady_golubogo_nila_ tis_abbaj_v_ehfiopii/2015-03-29-144 (accessed: 28.02.2020). (In Russian).

World Waterfall Database, 2020. Web page. URL: https://www.worldwaterfalldatabase.com/country/ Ethiopia/list (accessed: 28.02.2020). 